\title{
Arlequín. Una exposición para mirar y leer
}

Museo Picasso Málaga

7 de mayo de 2020

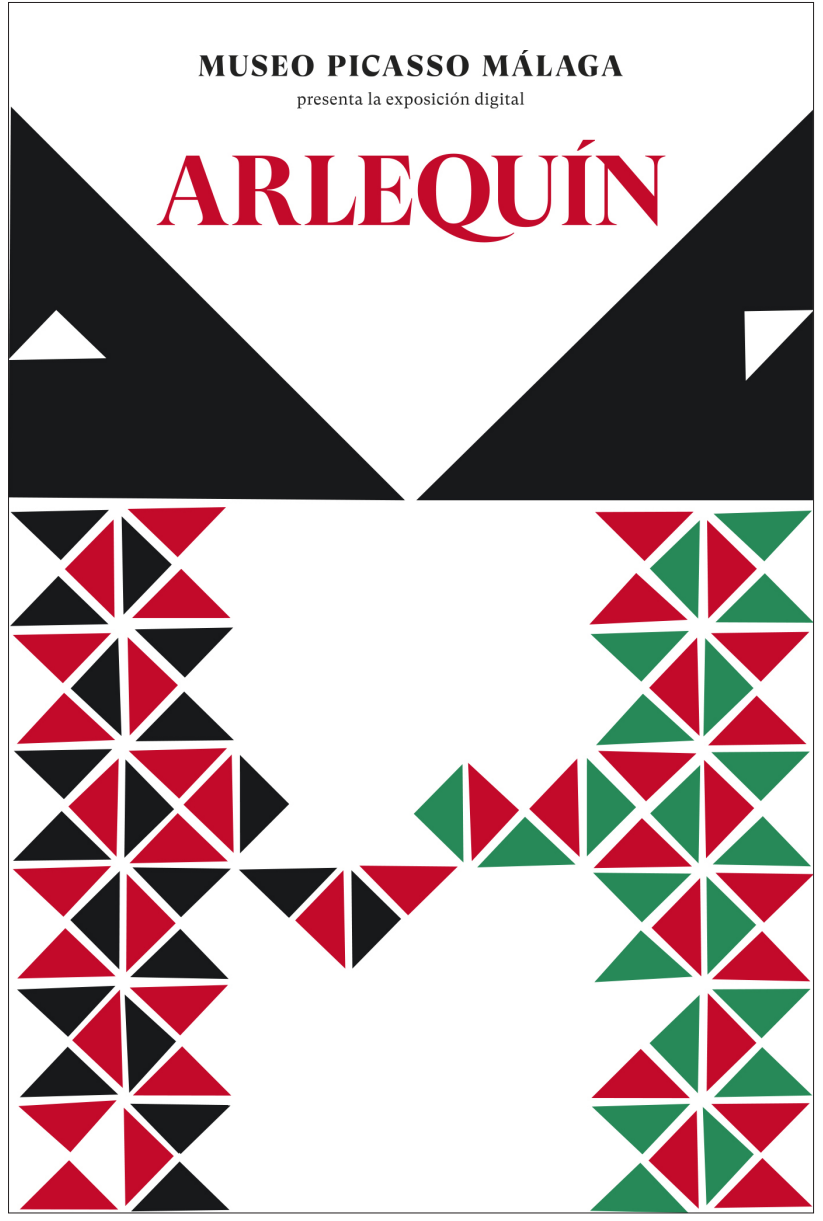

1. Cartel de la exposición (C) Museo Picasso Málaga

El Museo Picasso Málaga ofrece en su página web Arlequín. Una exposición para mirar y leer, la primera muestra digital en la historia de la institución, dedicada a la presencia del personaje más popular de la Commedia dell'arte en la obra de Pablo Picasso. Inaugurada virtualmente el 7 de mayo de 2020, se planteó en un primer momento llevarla a cabo en los espacios del museo de manera presencial con el pretexto de la apertura en la ciudad del Teatro del Soho CaixaBank en noviembre de 2019, iniciativa llevada a cabo por el ac- tor malagueño Antonio Banderas. El director, Lluís Pasqual, y José Lebrero, director artístico del museo, procedieron a desarrollar esta idea contando con la ayuda de organismos como el Piccolo Teatro di Milano, pero en marzo de 2020 se produjo la suspensión de gran parte de la actividad cultural debido al contundente impacto de la pandemia provocada por el Covid-19. Pese a estas circunstancias insólitas, el Museo Picasso es una de las instituciones museísticas de Málaga que han seguido trabajando para preparar exposiciones y actividades culturales, siendo la muestra que se presenta el fruto de todo el esfuerzo realizado [1].

Entre las instituciones privadas y públicas que han colaborado prestando objetos, películas y obras, en esta ocasión de manera digital, nos encontramos con la Bibliothèque Nationale de France, el Metropolitan Museum of Art, el Musée d'Orsay y, por supuesto, el Museu Picasso de BarceIona, que ha participado presentando el Arlequín de 1917, de importancia capital en la muestra que aquí comentamos. Cabe destacar las interesantes contribuciones del Piccolo Teatro di Milano, toda una serie de documentos gráficos sobre las distintas interpretaciones de la célebre obra Arlecchino, servitore di due padroni.

El recorrido de la exposición sigue un discurso a modo de libro ilustrado digital, organizándose en tres capítulos o bloques principales y un epílogo de constelaciones. La exposición comienza con «Picasso y sus arlequines», centrada en mostrar el lugar que ocupa este bufón dentro del universo picassiano. Este capítulo se divide en tres categorías, introduciendo en "Cronología de un personaje» al arlequín en la obra de Picasso a mediados de 1901, imagen que se extenderá hasta los últimos años del pintor. El mundo del circo aparece desde fechas muy tempranas, como podemos observar en el Proyecto para un cartel de carnaval del Musée Picasso de París, realizado en Barcelona a finales de 1899. En esta ocasión, Picasso nos presenta a Pierrot, el melancólico payaso de la Commedia dell'arte que es víctima del amor no correspondido de Columbine, que rompe su corazón al irse con Arlequín. Ya en el Arlequín sentado (1901) del 
Met, el bufón de la Commedia dell'arte se convierte en un alter ego del pintor malagueño, estando presente en la cultura popular del momento esta figura, aunque el ejemplo comentado tiene la peculiaridad de tener la cara blanca, cualidad de Pierrot. En 1904, afincado de manera definitiva en París, Picasso se vuelve un entusiasta de los teatros y cabarets marginales de Montmartre, gustándole sobre todo los payasos y comediantes ambulantes que conoce en los bares cercanos al Cirque Médrano. En obras de su período rosa como Familia del arlequín (1905), muestra a ese artista que tiene que entretener a la sociedad moderna, cargando con una vida errante y desarraigada. La exposición da un salto temporal de una década para llegar al Arlequín del MoMA, una obra sobria en lenguaje cubista compuesta por grandes áreas geométricas monocromas sobre fondo negro, terminada en el invierno de 1915.

La segunda categoría de este capítulo se titula «El Arlequín de 1917», centrada en la pintura al óleo que realizó en Barcelona durante el verano de 1917 y que forma parte de la colección del Museu Picasso de la Ciudad Condal por donación del artista en 1919 [2]. Picasso visitó la ciudad acompañando a los Ballets Russes de Serguéi Diáguilev para la presentación del ballet Parade en el Gran Teatre del Liceu, encargándose el artista de vestuarios y telón de boca. Este Arlequín es representado por Léonide Massine, primer bailarín de la compañía. Al contrario que el Arlequín del MoMA, en esta obra se produce la recuperación del sentido de la mímesis y la composición figurativa. Esta reconciliación con la pintura de los museos fue provocada por el ambiente generado a partir de la Primera Guerra Mundial, considerando boche (alemán) al cubismo, aunque el «Picasso clásico» fue cubista y clásico al mismo tiempo, inaugurando una etapa en la que pervive y modifica el cubismo y, por otro lado, van tomando lugar los elementos del clasicismo. En el Arlequín de 1917, el concepto de "clasicismo» es relativo, ya que no está representando a un personaje de la Commedia dell'Arte sino que es un actor disfrazado, siendo el disfraz el tema principal de la obra. Esta pintura viene acompañada de un estudio para la misma y una Cabeza de arlequín (1917), ambas pertenecientes al Museu Picasso de Barcelona.

«El teatro en la obra de Picasso» es la tercera y última categoría de este primer capítulo. Su objetivo es ubicar al teatro como una de las fuentes de inspiración del artista malagueño, empleando figuras de la Commedia dell'arte

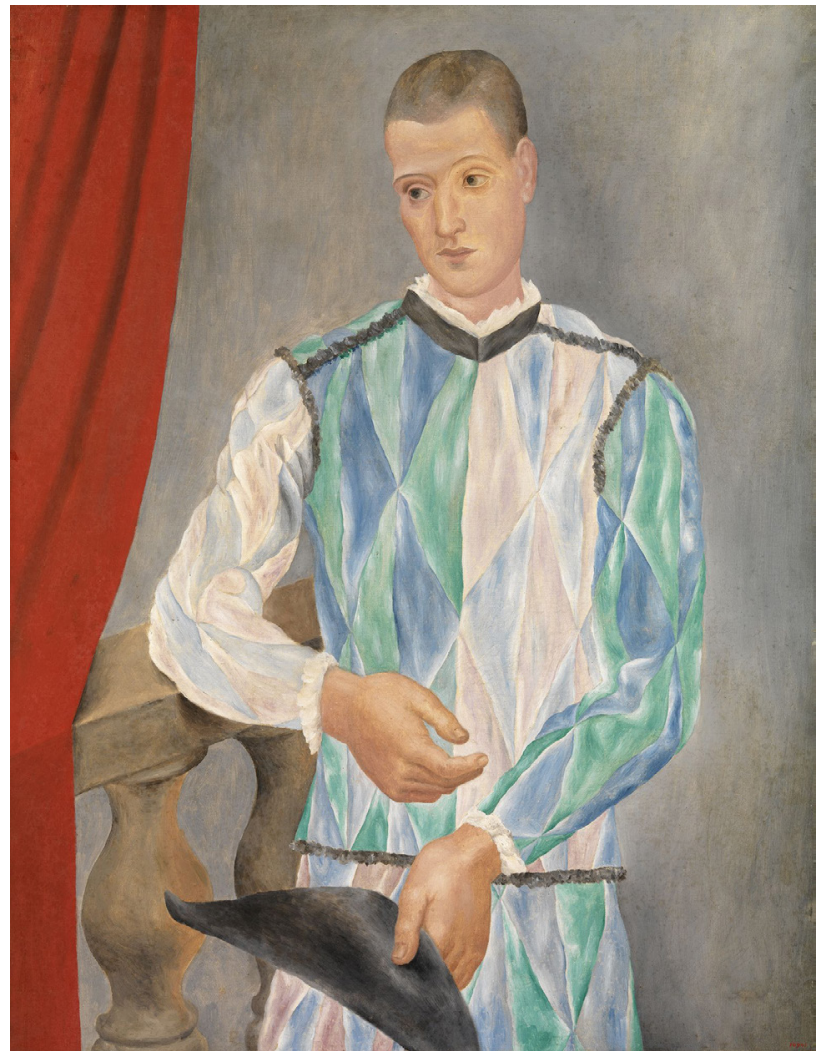

2. Pablo Picasso (1881-1973), Arlequín (Léonide Massine), 1917. Óleo sobre lienzo, 116 × $90 \mathrm{~cm}$. Museu Picasso, Barcelona. Donación del artista, 1919 (c) Museu Picasso, Barcelona. Fotografía, Gasull Fotografia @ Sucesión Pablo Picasso, VEGAP, Madrid, 2020

que pasarán a representar una tipología del artista moderno. El historiador del arte británico Douglas Cooper publicó un libro esencial sobre este aspecto del arte de Picasso titulado Picasso Theatre (1967). Para ilustrar esta categoría, se han seleccionado una serie de grabados pertenecientes a las Suites 156 y 347, procedentes de la Colección Fundación Bancaja (Valencia), poniendo en valor el lugar clave que ocupa este personaje en la producción de sus últimos años.

El segundo capítulo se titula «La Commedia dell'Arte», profundizando en «Una breve historia» sobre los orígenes de este género de teatro popular. Las primeras representaciones registradas se datan en el siglo XVI en Italia, interpretándose en plataformas al aire libre o en zonas populares como plazas por actores profesionales disfrazados y enmascarados, ofreciéndonos Peeter van Braedel una fiel reproducción en Escena de comedia del arte en un paisaje italiano, 


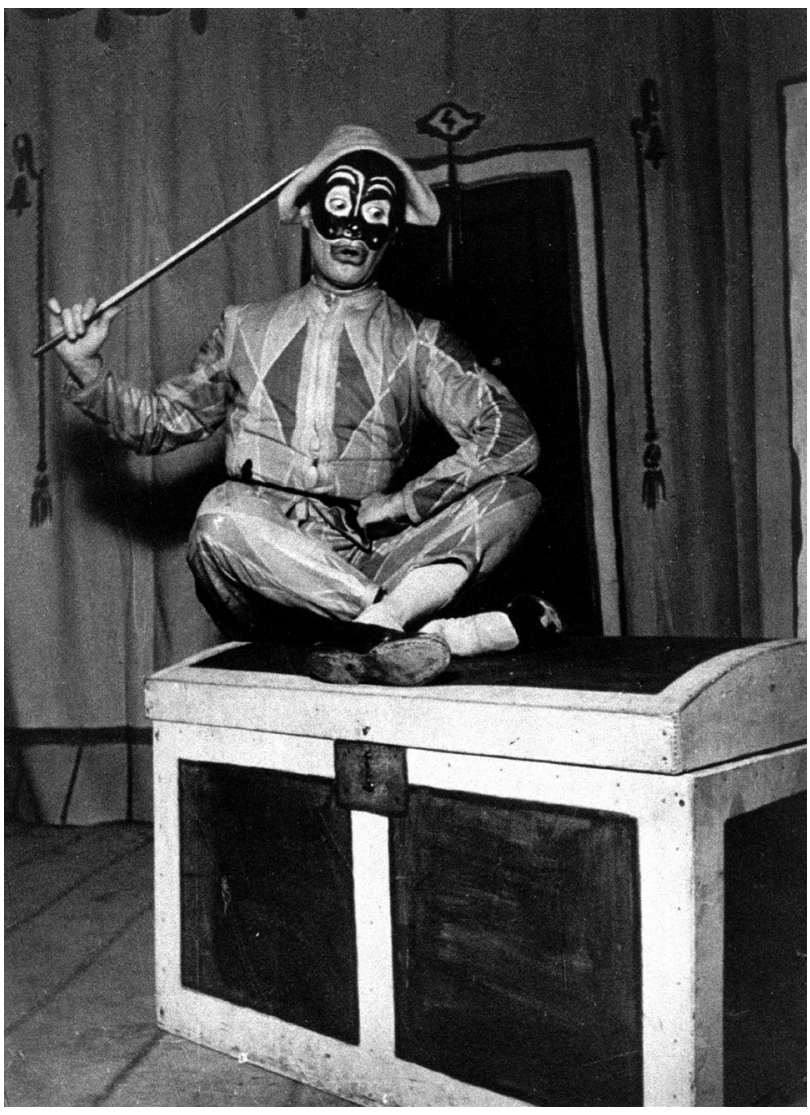

3. Cartel de la obra «Arlecchino servitore di due padroni». Berliner Festwochen. 1953-1954. Offset, 60 x 42 cm. C Archivio Piccolo Teatro Milano

préstamo del Groenigen Museum. La Commedia dell'Arte está conformada tanto por guion como por improvisación, teniendo como característica principal el lazzi, broma que formaba parte de una rutina, así como la pantomima, usada en el mayor de los casos por el personaje Arlequín. El público al que iba destinada era frecuentemente iletrado y los personajes suelen representar modelos reales exagerados, como la figura central de Pierrot en Los comediantes italianos (1720) de la NGA, obra realizada por el pintor rococó Antoine Watteau.

"Arlecchino», el segundo apartado de este capítulo, ahonda sobre la figura de nuestro protagonista. Arlequín es el más conocido de los zanni o criados, popularizado por el actor italiano Tristano Martinelli a finales del siglo XVI. Se caracteriza por vestir un traje cubierto por parches irregulares y un sombrero, ejemplificado en el Arlequín (1899-1890) de
Paul Cézanne, cortesía de la NGA, o el grabado del LACMA. Su papel es el de un sirviente bufón y astuto con una gran agilidad física, inmortalizado por Edgar Degas en El arlequín amarillo (ca. 1884) de la Fondation Bemberg. La máscara posee un chichón en la frente, ojos pequeños, nariz respingona, mejillas huecas y, en ocasiones, cejas tupidas, mostrada en el grabado Arlequín llorando (ca. 1730) de la NGA. El tercer apartado se ha denominado «Arlecchino, gran protagonista del Teatro Piccolo", centrado en presentar al primer teatro permanente de Italia: el Piccolo Teatro di Milano. Fundado en 1947, fue dirigido por el actor Giorgio Strehler y el empresario teatral Paolo Grassi, encargados de explorar la cultura vernácula italiana para presentar una adaptación de Arlecchino, servitore di due padroni, obra escrita por Carlo Goldoni y estrenada en Venecia en 1753. El Piccolo Teatro ha puesto a disposición un valioso contenido audiovisual que incluye un fragmento de la interpretación del actor Marcello Moretti en 1955, de Ferruccio Soleri en los años setenta, así como cartelería de los años cincuenta [3].

El último capítulo de esta exposición virtual lleva por título "Del estudio al camerino", abriendo con el apartado «Enmascaramiento». Parte de la idea promulgada por el crítico literario francés Roger Caillois en la que un tipo de juegos fomenta el mimicry, que viene a ser la imitación o el simulacro, en respuesta a la teoría sobre el juego recogida por Johan Huizinga en Homo Ludens (1938). Esta noción de simulacro se detecta también en el ámbito social y es, según Jean Baudrillard, la idea de vivir en una sociedad en la que nada es lo que es sino cómo se representa. La cualidad de enmascaramiento es propia de la representación teatral, como es el caso de la Máscara Noh del período Edo japonés del Met. Estas máscaras sirven, según Caillois, para tres objetivos esenciales: disimular, metamorfosear o aterrorizar, siendo un magnífico ejemplo el préstamo del Grand Palais de los dibujos de Katsushika Hokusai sobre las Máscaras de teatro (ca. 1814). La muestra señala el uso de las máscaras en la Alegoría de la simulación (ca. 1640-1650) de Lorenzo Lippi del Musée des Beaux-Arts d'Angers o el Demonio alado con una máscara (1876) de Odilon Redon, proveniente del Musée d'Orsay.

El segundo apartado se denomina "La máscara, el pintor y el actor», encontrándonos con un pequeño receso para explicar que el empleo de máscaras ya se sitúa en la antigüedad clásica, apreciándose en la Máscara romana del 
Met. Por otro lado, en el siglo XIX, artistas como James Ensor tienen obras dedicadas a este elemento que oculta las emociones como el Autorretrato con máscaras (1899) del Ménard Art Museum. Seguidamente, nos encontramos con antifaces que realizó Picasso en la década de los cincuenta, uno del Museu Picasso de Barcelona y otros dos pertenecientes a colecciones particulares. Además, el propio artista llegó a coleccionar máscaras tras el descubrimiento del llamado "arte negro", revelación que influyó en la producción picassiana a partir de 1907.

El último apartado lleva por título «Antesalas del espectáculo", confrontando el anonimato de los camerinos teatrales con los ateliers artísticos, más expuestos y pintorescos. Sin embargo, la construcción de la imagen del artista moderno tiene en este lugar un espacio íntimo que responde a un microcosmos personal. Los espacios que ocupará Picasso variarán en función del período personal del artista, de los espacios bohemios de principios de siglo a los burgueses del período clásico, y de los pequeños talleres que compartió en Barcelona a las mansiones y castillos del final de su vida. El interior de esos espacios con las obras y objetos que contienen será el reflejo del artista en cada momento de su vida. Este apartado viene acompañado por fotografías de Edward Quinn tomadas en La Californie (Cannes), en el taller de Vallauris, y en Notre-Dame-de-Vie (Mougins), formando parte todas ellas del Edward Quinn Archive en Hombrechtikon. Para terminar, se ofrece la imagen de un camerino de teatro vacío, ese espacio en el que se fragua la idea misma de las artes escénicas.

Como broche final de esta muestra, se ha organizado una «constelación» que analiza una selección de documentos escritos, sonoros y visuales que se pueden relacionar con el Arlequín de Picasso, siguiendo el método ideado por el filósofo Dieter Henrich. Se articula en tres «constelaciones»: una antología de textos que reúne poemas de autores como Guillaume Apollinaire o Paul Verlaine que dialogan con la pintura de Picasso, una filmoteca conformada por fragmentos de representaciones en el Piccolo Teatro a lo largo de más de medio siglo y, por último, una selección de libros para profundizar en el conocimiento del arlequín y del teatro en la obra de Picasso.

Pablo Salazar Jiménez Universidad de Málaga 